\title{
Dampak Non-Debt Tax Shield dan Resiko Bisnis Terhadap Struktur Modal Perusahaan Manufaktur Indonesia
}

\author{
Ani Wilujeng Suryani ${ }^{1}$, Mitcha Icha Sari $^{1}$ \\ ${ }^{1}$ Departemen Akuntansi, Fakultas Ekonomi dan Bisnis, Universitas Negeri Malang, Indonesia
}

Info Article

History Article:

Submitted: 11 July 2020

Revised: 19 September 2020

Accepted: 16 October 2020

\section{Keywords:}

Business Risk, Capital Structure, Non-Debt Tax Shield, Manufacturing Company

\begin{abstract}
Abstrak
Keputusan struktur modal menjadi salah satu keputusan penting yang diambil oleh manajer keuangan perusahaan karena pengelolaan yang salah menyebabkan kesulitan keuangan. Penelitian ini bertujuan untuk mengetahui pengaruh risiko bisnis dan non-debt tax shield terhadap struktur modal. Data dalam penelitian ini dikumpulkan dari laporan keuangan 137 perusahaan manufaktur di Indonesia selama periode 2014 sampai 2019. Pengujian hipotesis dilakukan dengan menggunakan regresi panel model fixed effect. Hasil penelitian menunjukkan bahwa non-debt tax shield berpengaruh negatif signifikan terhadap struktur modal, sedangkan risiko bisnis berpengaruh positif. Dengan demikian, perusahaan yang memiliki non-debt tax shield rendah akan memperbanyak utang untuk mendapatkan kompensasi pengurangan pajak dari beban bunga, sedangkan perusahaan dengan tingkat risiko tinggi lebih menyukai pendaan internal sehingga tingkat utang turun. Penelitian ini berkontribusi ke literatur dengan mengungkap faktor yang mempengaruhi penentuan tingkat utang perusahaan. Penelitian ini dapat dijadikan masukan bagi manajer perusahaan untuk mempertimbangkan risiko bisnis dan non-debt tax shield dalam menentukan struktur modal optimum sehingga dapat meningkatkan nilai perusahaan.
\end{abstract}

\section{The Impact of Non-Debt Tax Shield and Business Risk on Capital Structure of Manufacturing Companies in Indonesia}

\begin{abstract}
Capital structure decision is an important act made by company's financial manager as mismanagement causes financial distress. This study aims to determine the effect of non-debt tax shield and business risk on capital structure. The data in this study were collected from the financial reports of 137 manufacturing companies in Indonesia from 2014 to 2019. Hypothesis testing was carried out using a fixed effect panel regression model. The results showed that the non-debt tax shield had a significant negative effect on capital structure, while business risk had a positive effect. Thus, companies that have a low non-debt tax shield will increase their debt to get compensation for tax deductions from interest expenses, while companies with a bigh risk level prefer internal financing to decrease the debt level. This study contributes to the literature by uncovering the factors that influence the determination of corporate debt levels in manufacturing industries in Indonesia. The result of this research can be used by the company managers to consider business risk and non-debt tax shields in determining the optimum capital structure to increase the value of the company.
\end{abstract}

How to Cite: Suryani, A., W., \& Sari, M., I. (2020). Dampak Non-Debt Tax Shiled dan Resiko Bisnis Terhadap Struktur Modal Perusahaan Manufaktur Indonesia. Ekonomi Bisnis, 25(2), 108-119 
Struktur modal yang merupakan proporsi kombinasi pendanaan yang berasal utang dan ekuitas perusahaan (Arifin, 2005: 77) adalah salah satu faktor fundamental dalam perusahaan. Perusahaan dalam mengelola keuangan harus mampu memenuhi kebutuhan modal yang akan digunakan untuk kegiatan operasional ataupun investasi jangka panjang. Dengan demikian, manajemen keuangan perusahaan mengambil keputusan struktur modal untuk menentukan apakah kebutuhan modal akan dipenuhi dari sumber dana internal atau sumber dana eksternal (Sofat dan Singh, 2017).

Keputusan struktur modal dapat memengaruhi kondisi keuangan dan nilai perusahaan (Chadha dan Sharma, 2015). Oleh karena itu, dalam keputusan struktur modal manajemen harus dapat menentukan pilihan sumber dana yang paling efisien dan menguntungkan bagi perusahaan baik jangka pendek maupun dimasa yang akan datang untuk menghindari kesulitan keuangan (financial distress) (Sofat dan Singh, 2017).

Dalam pengambilan keputusan terkait dengan struktur modal, perusahaan perlu mempertimbangkan non-debt tax shield dan risiko bisnis (Sheikh dan Wang, 2011; Chadha dan Sharma, 2015). Non-debt tax shield merupakan pengurang pajak yang berasal dari beban depresiasi, amortisasi, dan biaya research and development $(\mathrm{R} \& \mathrm{D})$. Ketiga komponen ini dapat digunakan sebagai pengganti manfaat pajak dari beban bunga akibat adanya penggunaan utang (De Angelo dan Masulis, 1980). Tingginya non non-debt tax shield akan menambah beban perusahaan sehingga pajak penghasilan menjadi rendah dan laba setelah pajak menjadi lebih tinggi dibandingkan dengan perusahaan yang tidak memiliki non-debt tax shield (Gomez, et al., 2014). Dengan non-debt tax shield dan tingkat laba perusahaan yang tinggi maka perusahaan cenderung menggunakan lebih sedikit utang untuk menghindari terjadinya financial distress
(Cortez dan Susanto, 2012). Hal ini berarti non-debt tax shield memiliki pengaruh negatif terhadap struktur modal (Bayrakdaroglu, et al., 2013; Cortez dan Susanto, 2012; Gomez, et al., 2014; Martín dan Hoffmann, 2017).

Hasil penelitian terdahulu menemukan bahwa perusahaan dengan non-debt tax shield yang tinggi memiliki kecenderungan untuk menggunakan sumber dana eksternal yang berasal dari utang dibandingkan perusahaan dengan non-debt tax shield yang rendah (Chadha dan Sharma, 2015; Awan dan Amin, 2014; Kouki dan Said, 2012; Mulyadi, et al., 2016). Non-debt tax shield yang tinggi mencerminkan banyaknya aset berwujud yang dimiliki oleh perusahaan sehingga biaya depresiasi juga tinggi (Mulyadi, et al., 2016). Aset berwujud ini bisa dijadikan sebagai jaminan utang (Kouki dan Said, 2012). Hal ini menandakan pengaruh positif non-debt tax shield terhadap struktur modal (Chadha dan Sharma, 2015; Awan dan Amin, 2014; Kouki dan Said, 2012; Mulyadi, et al., 2016). Namun, hasil penelitian lain menyatakan bahwa non-debt tax shield tidak berpengaruh terhadap struktur modal (Abba, et al., 2018; Sheikh dan Wang, 2011; Tamam dan Wibowo, 2017; Lourenço dan Oliveira, 2017). Hasil yang tidak konsisten dari penelitian terdahulu disebabkan karena perbedaan sampel atau lokasi, misalnya penelitian di Portugal pada usaha mikro (Lourenço dan Oliveira, 2017), sedangkan penelitian lain dilakukan pada perusahaan yang berukuran besar.

Hal lain yang bisa memengaruhi struktur modal adalah risiko bisnis. Risiko bisnis dapat tercermin dari laba perusahaan (Lim, 2012). Tingginya tingkat risiko bisnis bisa berakibat pada laba yang tidak stabil atau fluktuatif sehingga perusahaan menggunakan utang untuk memenuhi kebutuhan struktur modal karena laba tidak mampu untuk memenuhi kebutuhan operasional perusahaan (Chen, et al., 2014). Hal ini menunjukkan pengaruh positif risiko bisnis 
terhadap struktur modal (Chadha dan Sharma, 2015; Chen, et al., 2014; Sofat dan Singh, 2017). Hasil penelitian lain menunjukkan pengaruh negatif risiko bisnis terhadap struktur modal (Sheikh dan Wang, 2011; Khémiri dan Noubbigh, 2018; Lim, 2012). Perusahaan yang telah memiliki risiko bisnis yang tinggi cenderung menggunakan sumber dana internal dan mengurangi utang untuk memenuhi kebutuhan struktur modal, karena tingginya risiko dapat meningkatkan terjadinya gagal bayar ketika utang jatuh tempo (Sheikh dan Wang, 2011). Namun, ada pula penelitian yang tidak menemukan adanya pengaruh risiko bisnis terhadap struktur modal (Abba, et al., 2018; Lourenço dan Oliveira, 2017; Wijaya dan Jessica, 2017). Hasil yang tidak konsisten dari penelitian terdahulu dikarenakan adanya perbedaan indikator pengukuran variabel dan obyek penelitian. Penelitian terdahulu memasukkan biaya depresiasi dalam indikator pengukuran variabel dengan obyek penelitian yaitu perusahaan yang terdaftar di bursa Nigeria atau dilakukan di negara belum berkembang (Abba, et al., 2018).

Penelitian ini bertujuan untuk mengetahui pengaruh variabel non-debt tax shield dan risiko bisnis terhadap struktur modal. Penelitian ini didasari oleh inkonsistensi hasil dari penelitian sebelumnya mengenai hubungan non-debt tax shield dan risiko bisnis terhadap struktur modal. Hasil penelitian terdahulu yang masih ditemukan perbedaan, maka perlu dilakukan penelitian ulang mengenai faktorfaktor tersebut dengan periode dan sampel yang berbeda dari penelitian sebelumnya. Penelitian ini berkontribusi terhadap literatur terkait struktur modal dengan memberikan gambaran penggunaan struktur modal dalam perusahaan manufaktur di Indonesia. Dengan adanya penelitian ini diharapkan manajer perusahaan mempertimbangkan risiko bisnis dan non-debt tax shield dalam menentukan struktur modal optimum sehingga dapat meningkatkan nilai perusahaan.

Pecking order theory merupakan salah satu teori yang membahas mengenai struktur modal perusahaan. Menurut teori ini, perusahaan akan mendahulukan pendaanan internal yang bersumber pada keuntungan, ketimbang menggunakan hutang atau penerbitan saham baru (Myers, 1984). Hal ini dikarenakan minimnya biaya eksplisit dalam penggunaan dana internal, tetapi penggunaan dana eksternal menambah adanya monitoring pihak eksternal sehingga tanpa adanya pendaaan internal, perusahaan lebih mengutamakan utang daripada menerbitkan saham (Sugeng, 2017: 330).

Teori lain dalam struktur modal yang mempertimbangkan dan mempertemukan keuntungan serta kerugian dari penggunaan sumber dana utang disebut trade-off theory (Kraus dan Litzebnerger, 1973; Myers dan Majluf, 1984). Teori ini merupakan gabungan antara pemanfaatan utang dan risiko yang ditimbulkan oleh utang (Brigham dan Houston, 2014). Menurut teori ini, pendanaan dari utang memberikan manfaat (benefit) berupa kompensasi pengurangan pajak, tetapi sekaligus menimbulkan biaya (cost) atau kerugian (Cekrezi, 2013). Kerugian pendanaan dari utang dapat menimbulkan peluang terjadinya kondisi kesulitan keuangan (financial distress) dan kebangkrutan (bankruptcy). Ketika dalam struktur modal perusahaan terdapat proporsi utang yang cukup besar, maka peluang risiko terjadinya kesulitan keuangan perusahaan yang dapat mengakibatkan kebangkrutan semakin tinggi.

$$
\text { Meskipun trade-off theory tidak }
$$
merumuskan besarnya kombinasi untuk mendapatkan struktur modal yang optimal, tetapi teori ini memberikan tiga masukan penting (Atmaja, 2008). Pertama, perusahaan yang memiliki risiko bisnis yang tinggi lebih berpeluang mengalami financial distress sehingga disarankan agar perusahaan semacam ini 
menggunakan sedikit utang. Kedua, perusahaan dengan tangible dan marketable assets yang tinggi bisa memanfaatkan komponen asetnya untuk mendapatkan dana eksternal dari utang dibandingkan perusahaan yang memiliki komponen intangible assets (seperti goodwill, hak paten, hak cipta) yang besar. Hal ini dikarenakan intangible assets lebih susah untuk dikonversi menjadi kas sehingga financial distress menyebabkan aset ini mudah kehilangan nilai. Ketiga, perusahaan bisa memiliki lebih banyak utang jika perusahaan tersebut memiliki laba yang tinggi serta pembayaran pajak yang tinggi karena adanya beban bunga dari utang bisa menurunkan jumlah pajak yang harus dibayar.

Ada dua jenis struktur modal yang menunjukkan proporsi pendanaan perusahaan yang berasal dari sumber dana eksternal utang, dan sumber dana internal yaitu ekuitas yang berupa ekuitas saham biasa dan saham preferen (Horne, et al., 2012). Pertama adalah simple capital structure dimana perusahaan mendanai semua kegiatannya dengan modal sendiri, dan yang kedua adalah complex capital structure dimana kombinasi modal sendiri dan utang digunakan oleh perusahaan untuk mendanai kegiatan operasionalnya (Fahmi, 2011). Manajemen harus memikirkan proporsi yang tepat antara penggunaan pendanaan yang berasal dari utang dan modal sendiri untuk mengoptimalkan struktur modal (Brigham dan Houston, 2011). Hal ini dikarenakan keoptimuman struktur modal bisa berdampak pada maksimalnya nilai perusahaan atau malah bisa menaikkan nilai perusahaan saat ini (Sugeng, 2017: 320).

Keoptimalan struktur modal bisa dicapai ketika manfaat bebas pajak sama dengan biaya kerugian yang ditimbulkan akibat utang (Chadha dan Sharma, 2015). Dengan mempertimbangkan sisi keuntungan dan kerugian dari penggunaan utang, maka ada dua kondisi yang bertolak belakang. Pertama, semakin tinggi porsi utang maka semakin besar keuntungan dari pajak sehingga mendorong kenaikan nilai perusahaan. Kedua, semakin tinggi porsi utang maka semakin tinggi peluang terjadinya financial distress sehingga dapat menurunkan nilai perusahaan (Sugeng, 2017: 320).

Biaya bunga yang timbul akibat utang dapat dijadikan sebagai pengurang pajak (Modigliani dan Miller, 1958). Perisai pajak bunga tersebut memberikan insentif bagi perusahaan untuk menggunakan utang (Lim, 2012). Selain utang, penyusutan aset tetap dan investment tax credit juga dapat mengkompensasi pembayaran pajak (Gomez, et al., 2014). Dalam hal ini, non-debt tax shield berkaitan dengan pemotongan pajak dari depresiasi dan kredit pajak dari investasi (Lim, 2012). Non-debt tax shield dapat digunakan sebagai pengganti manfaat penghematan pajak dari utang (De Angelo dan Masulis, 1980). Non-debt tax shield dihitung menggunakan rasio penyusutan terhadap total aset (Lourenço dan Oliveira, 2017; Gomez, et al., 2014; Martín dan Hoffmann, 2017). Semakin tinggi rasio ini menunjukkan bahwa lebih banyak ketersediaan perisai pajak depresiasi (Chadha dan Sharma, 2015).

Non-debt tax shield bisa membawa pengaruh positif terhadap struktur modal (Kouki dan Said, 2012; Sharah, et al., 2014; Bayrakdaroglu, et al., 2013; Chadha dan Sharma, 2015; Khémiri dan Noubbigh, 2018). Perusahaan dengan non-debt tax shield yang tinggi cenderung menggunakan lebih banyak utang (Chadha dan Sharma, 2015). Hal ini dikarenakan non-debt tax shield yang lebih tinggi mencerminkan lebih banyak aset berwujud perusahaan (Mulyadi, et al., 2016). Aset berwujud yang dimiliki oleh perusahaan dapat dijadikan sebagai jaminan untuk utang (Kouki dan Said, 2012). Namun, penelitian lain menunjukkan hubungan yang negatif antara non-debt tax shield dengan struktur modal (Adhegaonkar dan Indi, 2012; Cortez dan Susanto, 2012; Gomez, et al., 2014; Lim, 2012; Martín dan Hoffmann, 2017). Non-debt tax shield 
dapat digunakan sebagai pengganti manfaat pajak dari penggunaan utang (De Angelo dan Masulis, 1980). Perusahaan dengan tingkat Non-debt tax shield yang tinggi tidak perlu menggunakan lebih banyak utang dalam memenuhi kebutuhan struktur modal karena manfaat pajak dari beban depresiasi dapat menambah arus kas perusahaan (Lim, 2012). Berdasarkan uraian di atas maka hipotesis yang dapat dirumuskan pada penelitian ini yaitu:

$\mathrm{H}_{1} \quad$ : Non-debt tax shield berpengaruh positif terhadap struktur modal.

Risiko bisnis adalah risiko yang muncul ketika perusahaan tidak mampu mencukupi biaya operasionalnya (Chandra, 2014). Biaya tetap operasional dapat meningkatkan laba perusahaan apabila terjadi peningkatan volume penjualan karena biaya tetap operasional tidak berubah. Namun, ketika perusahaan mengalami penurunan volume penjualan maka akan meningkatkan peluang terjadinya kebangkrutan karena perusahaan tidak mampu menutupi biaya tetap operasionalnya atau mengalami kerugian (Sugeng, 2017). Risiko bisnis dapat tercermin dalam laba perusahaan (Lim, 2012). Semakin tinggi volume penjualan akan memberikan peluang untuk memperoleh tingkat laba yang semakin tinggi pula. Namun, ketika terjadi penurunan volume penjualan maka tingkat laba juga akan semakin rendah dan tingkat risiko yang dihadapi oleh perusahaan semakin tinggi (Chadha dan Sharma, 2015). Tingginya tingkat risiko bisnis yang dihadapi perusahaan dapat meningkatkan terjadinya gagal bayar ketika jatuh tempo (Sheikh dan Wang, 2011).

Penelitian terdahulu menemukan adanya pengaruh positif risiko bisnis terhadap struktur modal (Chadha dan Sharma, 2015; Chen, et al., 2014; Kouki dan Said, 2012; Sofat dan Singh, 2017). Tinggi rendahnya biaya tetap operasional yang ditanggung oleh perusahaan berdampak pada besar kecilnya risiko bisnis yang dihadapi oleh perusahaan (Chadha dan Sharma, 2015). Perusahaan dengan risiko yang kecil biasanya memiliki laba yang tinggi sehingga memiliki kemampuan yang lebih tinggi untuk membayar kewajiban kepada kreditur (Chen, et al., 2014). Namun, penelitian lain menunjukkan hubungan negatif antara risiko bisnis dengan struktur modal (Sheikh dan Wang, 2011; Khémiri dan Noubbigh, 2018; Lim, 2012; Yunita dan Aji, 2018). Perusahaan dengan tingkat risiko bisnis yang tinggi akan meningkatkan terjadinya financial distress (Sofat dan Singh, 2017). Perusahaan dengan risiko bisnis tinggi cenderung menggunakan lebih sedikit utang untuk memenuhi kebutuhan struktur modal, karena bertambahnya utang bisa meningkatkan terjadinya gagal bayar ketika jatuh tempo (Sheikh dan Wang, 2011). Berdasarkan penelitian terdahulu maka hipotesis yang dapat dirumuskan pada penelitian ini yaitu:

$\mathrm{H}_{2}$ : risiko bisnis berpengaruh negatif terhadap struktur modal.

\section{METODE}

Penelitian ini adalah penelitian kuantitatif eksplanatif pada perusahaan manufaktur yang terdaftar di Bursa Efek Indonesia (BEI). Perusahaan manufaktur dipilih karena perusahaan ini memiliki kontribusi terbesar pada produk domestik bruto (BPS 2017). Dari 190 perusahaan, terdapat 139 perusahaan yang terdaftar sejak 2016, tetapi dua diantaranya mengalami delisting. Dengan demikian penelitian ini menggunakan data 137 perusahaan manufaktur dari 2014 hingga 2019. Data yang dibutuhkan dalam penelitian ini diperoleh melalui database Osiris.

Struktur modal merupakan proporsi penggunaan pendaanan internal dan eksternal. Dalam penelitian ini, debt ratio digunakan sebagai ukuran untuk melihat struktur modal yang 
berbasis pada nilai buku. Debt ratio (total debt/ total aset) ini juga bisa mencerminkan kesulitan keuangan yang dihadapi perusahaan (Acaravci, 2015; Chadha dan Sharma, 2015; Cortez dan Susanto, 2012; Murniati, 2016; Rouf, 2015; Sofat dan Singh, 2017).

Variabel bebas yang pertama yaitu nondebt tax shield merupakan perbandingan biaya depresiasi, amortisasi serta biaya research and development terhadap aset total (Gao, 2016). Non-debt tax shield berkaitan dengan tax saving dari depresiasi dan investment tax credit (Lim, 2012). Variabel bebas kedua yaitu risiko bisnis dapat diukur menggunakan perbandingan antara standar deviasi EBIT tiga tahun terakhir terhadap aset total (Sheikh dan Wang, 2011; Dufour, et al., 2018; Khémiri dan Noubbigh, 2018; Lim, 2012; Lourenço dan Oliveira, 2017; Yunita dan Aji, 2018). Dengan demikian persamaan regresi utama adalah sebagai berikut:

$\mathrm{Y}=\alpha+\beta_{1} \mathrm{NDTS}_{\mathrm{it}}+\beta_{2}$ Risk $_{\mathrm{it}}+\varepsilon \ldots \ldots \ldots \ldots(1)$

Dalam penelitian ini, ada dua variabel kontrol yang digunakan yaitu ukuran perusahaan yang bisa mempengaruhi kestabilan arus kas dan kemudahan pendanaan eksternal (Dufour, et al., 2018; Fattouh, et al., 2008; Gomez, et al., 2014; Khémiri dan Noubbigh, 2018; Köksal dan Orman, 2014; Sofat dan Singh, 2017) serta umur perusahaan sebagai kontrol atas reputasi perusahaan (Khémiri dan Noubbigh, 2018). Ukuran perusahaan dihitung berdasarkan total aset yang dimiliki, sedangkan umur perusahaan dihitung dari tahun observasi dikurangi tahun berdirinya perusahaan. Dengan demikian model persamaan regresi dengan memasukkan variabel kontrol adalah sebagai berikut:

$\mathrm{Y}=\alpha+\beta_{1}$ NDTS $_{\text {it }}+\beta_{2}$ Risk $_{\text {it }}+\beta_{3}$ Size $_{\text {it }}+\beta_{4}$ Age $_{\text {it }}$

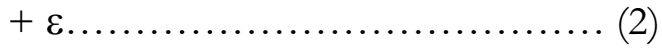

Penelitian ini menggunakan data time series dan cross-section sehingga digunakan regresi data panel. Dalam analisis data panel ada tiga pilihan model estimasi yang dapat dilakukan yaitu common effect, fixed effect, dan random effect. Setelah melakukan uji Hausman dan uji redundant atau Chow test, model fixed effect dipilih karena merupakan model yang terbaik (lihat Tabel 1). Model fixed effect mengasumsikan adanya perbedaan intercept dari setiap individu perusahaan, sedangkan slope antar individu adalah tetap (sama).

Tabel 1. Uji Pemilihan Model

\begin{tabular}{llrrr}
\hline Uji & $\boldsymbol{\chi}^{\mathbf{2}}$ & df & \multicolumn{1}{c}{ Prob } & Model \\
\hline Hausman & 180,12 & 4 & 0,000 & Fixed effect \\
Chow test & 738,31 & 136 & 0,000 & Fixed effect \\
\hline
\end{tabular}

\section{HASIL DAN PEMBAHASAN}

Hasil statistik deskriptif variabel dalam penelitian yang memberikan gambaran sifat data tersaji dalam Tabel 2. Dari 137 perusahaan manufaktur, nilai rerata struktur modal sebesar 65,4\%. Hal mengindikasikan bahwa perusahaan manufaktur di Indonesia memiliki struktur modal yang cukup sehat dimana terdapat kecukupan aset untuk membayar kewajiban. Lebih lanjut, rerata risiko bisnis hanya sebesar 0,032 yang berarti bahwa sebagian besar perusahaan manufaktur di Indonesia memiliki risiko bisnis yang rendah (Khémiri dan Noubbigh 2018). Hal ini bisa terjadi karena rata-rata umur perusahaan manufaktur yang masuk dalam penelitian ini adalah 37 tahun. Dengan demikian perusahaan manufaktur bisa dikatakan merupakan indutri dalam fase dewasa atau mature (Noordin dan Mohtar 2014). Tuanya umur perusahaan juga bisa mengindikasikan kemapanan keuangan perusahaan sehingga perusahaan tidak banyak memiliki utang. Selain itu, ukuran perusahaan 
yang diukur dengan logaritma natural dari aset total yang juga menunjukkan bahwa perusahaan manufaktur di Indonesia tergolong memiliki aset yang cukup besar/tinggi (Sofat dan Singh, 2017).
Sementara itu hasil dalam Tabel 3 menunjukkan korelasi antar variabel dalam penelitian ini. Berdasarkan hasi korelasi secara bivariate, risiko bisnis memiliki hubungan positif

Tabel 2. Hasil Statistik Deskriptif

\begin{tabular}{lrrrrr}
\hline & Mean & Median & Max & \multicolumn{1}{c}{ Min } & Stdev \\
\hline Y Capital Structure & 0,654 & 0.566 & 9.969 & 0,332 & 0,657 \\
X $_{1}$ NDTS & 0,033 & 0.028 & 0,332 & 0,0001 & 0,029 \\
X $_{2}$ Risk & 0,032 & 0.022 & 0,472 & 0,0004 & 0,040 \\
Z $_{1}$ Size & 19,564 & 20,689 & 26,587 & 10,372 & 3,862 \\
Z $_{2}$ Age & 37,08 & 38 & 102 & 5,00 & 13,752 \\
\hline
\end{tabular}

Sumber: Data Primer diolah peneliti, 2020

Dengan besarnya jumlah aset total yang dimiliki perusahaan, maka bisa dipahami jika risiko bisnis perusahaan manufaktur di Indonesia cukup rendah yaitu hanya sebesar 0,013 (Khémiri dan Noubbigh 2018). Hasil ini juga mengindikasikan tingginya tingkat aset yang dimiliki perusahaan yang bisa digunakan sebagai kolateral utang. Namun demikian, besarnya aset total yang dimiliki oleh perusahaan tidak serta merta membuat nilai non-debt tax shield yang tinggi. Nondebt tax shield yang diukur sebagai proporsi depresiasi terhadap aset total menunjukkan nilai 0,033 yang mengindikasikan bahwa perusahaan manufaktur di Indonesia memiliki beban depresiasi atau amortisasi yang cukup rendah (Martín dan Hoffmann 2017). Penjelasan yang mungkin bisa menjawab kondisi ini adalah karena metode penyusutan yang banyak dipilih dan digunakan oleh perusahaan manufaktur di Indonesia yaitu metode penyusutan garis lurus. Metode ini mengalokasikan harga aset selama beberapa tahun dengan jumah yang sama, sehingga pembebanannya tidak dipengaruhi oleh perubahan produktifitas dan efisiensi aset (Hery, 2014). signifikan dengan struktur modal sedangkan umur perusahaan memiliki hubungan yang negatif. Non-debt tax shield berkorelasi positif dengan risiko bisnis dan umur perusahaan, meskipun korelasinya cukup rendah. Umur perusahaan juga berkorelasi signifikan dengan semua variabel lainnya kecuali dengan struktur modal.

Berikutnya, hasil analisis data penelitian yang tersaji dalam Tabel 4 menunjukkan bahwa non-debt tax shield berpengaruh negatif terhadap struktur modal yang berarti bahwa semakin tinggi non-debt tax shield maka semakin rendah utang dalam memenuhi kebutuhan struktur modal. Hasil penelitian ini konsisten dengan penelitian Cortez dan Susanto (2012), Gomez et al. (2014), Lim (2012), serta Martín dan Hoffmann (2017). Non-debt tax shield memiliki nilai rata-rata sebesar 0,033 yang berarti bahwa tingkat non-debt tax shield perusahaan manufaktur di Indonesia cukup rendah. Meskipun demikian, perusahaan manufaktur cenderung memiliki aset tetap yang tinggi karena banyaknya kepemilikan aset yang misalnya berupa mesin untuk produksi, kendaraan logistik serta gedung pabrik. Hal ini 
Tabel 3. Hasil Analisis Korelasi Antar Variabel

\begin{tabular}{llllll}
\hline & \multicolumn{1}{c}{$\mathbf{Y}$} & \multicolumn{1}{c}{$\mathbf{X}_{1}$} & \multicolumn{1}{c}{$\mathbf{X}_{2}$} & \multicolumn{1}{c}{$\mathbf{Z}_{1}$} & $\mathbf{Z}_{2}$ \\
\hline Y Cap.Structure & 1 & & & & \\
X $_{1}$ NDTS & 0,039 & 1 & & & \\
X $_{2}$ Risk & $0,389^{* * *}$ & $0,207^{* * *}$ & 1 & & \\
$Z_{1}$ Size & $-0,154^{* * *}$ & $-0,022$ & $-0,031$ & 1 & \\
$Z_{2}$ Age & $-0,038$ & $0,240^{* * *}$ & $-0,093^{* *}$ & $0.109^{*}$ & 1 \\
\hline
\end{tabular}

Sumber: Data Primer diolah peneliti, 2020

Tabel 4. Hasil Analisis Uji F dan t

\begin{tabular}{lrrrrrr}
\hline \multicolumn{1}{c}{ Variable } & Coefficient & \multicolumn{1}{c}{ t-Stat } & p-value & F stat & p-value & \multicolumn{1}{c}{$\mathbf{R}^{2}$} \\
\hline Model 1 & & & & 6,359 & 0,000 & 0,566 \\
$\mathrm{C}$ & 0.474 & 12.931 & 0.000 & & & \\
$\mathrm{X}_{1}$ & -0.627 & -0.669 & 0.504 & & & \\
$\mathrm{X}_{2}$ & 6.000 & 10.577 & 0.000 & & & \\
Model 2 & & & & 9,347 & 0,000 & 0,661 \\
$\mathrm{C}$ & 16.556 & 12.738 & 0.000 & & & \\
$\mathrm{X}_{1}$ & -3.325 & -3.900 & 0.000 & & & \\
$\mathrm{X}_{2}$ & 2.930 & 5.328 & 0.000 & & & \\
$\mathrm{Z}_{1}$ & -0.983 & -13.457 & 0.000 & & & \\
$\mathrm{Z}_{2}$ & 0.090 & 8.920 & 0.000 & & & \\
\hline
\end{tabular}

Sumber: Data Primer diolah peneliti, 2020

berbeda dengan perusahaan jasa misalnya perbankan yang cenderung memiliki aset lancar yang lebih tinggi karena hartanya sebagian besar berupa kas atau surat-surat berharga yang memungkinkan konversi ke kas yang cepat (Atmaja, 2008). Oleh karena itu, perusahaan manufakur cenderung memiliki biaya depresiasi yang besar. Biaya penyusutan merupakan pengurang penghasilan dan bisa dijadikan insentif bagi perusaahan untuk mengurangi pajak (Khémiri dan Noubbigh, 2018). Dengan demikian perusahaan dengan tingkat aset tetap yang tinggi memiliki biaya penyusutan yang besar akan cenderung memiliki struktur modal yang kecil atau lebih banyak menggunakan modal sendiri karena sudah ada pengurang pajak.
Sebaliknya, kepemilikan aset tetap yang rendah berdampak pada rendahnya biaya penyusutan dan rendahnya pengurang pajak. Hal ini mendorong perusahaan untuk menggunakan lebih banyak utang dibandingkan dengan ekuitas dalam struktur modal untuk mendapat manfaat pengurang pajak dari bunga yang dibayarkan atas utang.

Hasil penelitian ini mendukung trade-off theory yang menunjukkan bahwa perusahaan akan menggunakan pendanaan dari utang karena dapat memberikan manfaat berupa penghematan pajak selama rasio utang tidak melampaui batas struktur modal optimum (Kraus dan Litzenberger, 1973). Berdasarkan hal tersebut maka dapat disimpulkan bahwa 
perusahaan manufaktur di Indonesia mempertimbangkan tingkat non-debt tax shield dalam pengambilan keputusan struktur modal.

Hasil penelitian ini juga menunjukkan bahwa risiko bisnis berpengaruh positif terhadap struktur modal, berbeda dengan yang dihipotesiskan. Risiko bisnis perusahaan berkaitan dengan kelangsungan hidup dan kemampuan perusahaan untuk membayar utangnya (Sofat dan Singh, 2017). Tingkat risiko bisnis memengaruhi kemampuan perusahaan untuk memperoleh dana karena dijadikan sebagai pertimbangan investor dalam menanamkan modal dan kreditor dalam memberikan pinjaman (Chen et al., 2014). Penelitian ini menunjukkan bahwa semakin tinggi tingkat risiko bisnis, maka semakin besar tingkat utang yang digunakan untuk memenuhi kebutuhan struktur modal. Hasil penelitian ini konsisten dengan penelitian Chen, et al., (2014), Kouki dan Said (2012), serta Sofat dan Singh (2017). Hasil penelitian ini juga sesuai dengan pecking order theory yang menyebutkan hubungan yang positif antara tingkat risiko bisnis dengan struktur modal yang lebih dibiayai oleh utang (Myers, 1984).

Salah satu alasan yang bisa menyebabkan penelitian ini memberikan hasil yang berbeda adalah karena rerata risiko bisnis perusahaan manufaktur di Indonesia yang sangat rendah yaitu hanya 3,2\%. Dengan demikian, meskipun hubungan antara struktur modal dan risiko bisnis adalah positif, perusahaan pada penelitian ini memiliki risiko bisnis yang cukup rendah sehingga masih memungkinkan pendanaan dari utang. Munculnya peluang untuk menggunakan lebih banyak utang bagi perusahaan memberikan insentif karena utang dapat memberikan manfaat berupa penghematan pajak. Perusahaan yang memiliki risiko bisnis yang tinggi cenderung memilih menggunakan lebih sedikit utang untuk menghindari terjadinya financial distress, atau lebih mementingkan pendanaan internal. Akan tetapi karena sampel perusahaan pada penelitian ini memiliki tingkat risiko bisnis yang rendah, maka penambahan utang ini tidak menyebabkan risiko kebangkrutan karena adanya total aset yang cukup dijadikan sebagai jaminan utang. Berdasarkan temuan penelitian berikut penjelasannya tersebut maka dapat disimpulkan bahwa perusahaan manufaktur di Indonesia juga mempertimbangkan tingkat risiko bisnis dalam menentukan keputusan pendanaan atau struktur modal.

\section{SIMPULAN DAN SARAN}

Penelitian ini berfokus pada pengaruh non-debt tax shield dan risiko bisnis terhadap struktur modal perusahaan manufaktur di Indonesia. Hasil penelitian menunjukkan bahwa non-debt tax shield berpengaruh negatif signifikan terhadap struktur modal. Temuan ini konsisten dengan penelitian terdahulu yang menemukan bahwa semakin rendah non-debt tax shield maka akan meningkatkan utang perusahaan dalam memenuhi kebutuhan struktur modal. Selain itu, hasil penelitian ini juga mendukung trade-off theory yang menyatakan bahwa pendanaan dari utang memberikan keuntungan berupa penghematan pajak sehingga perusahaan lebih baik menggunakan manfaat dari utang tersebut selama tidak melampaui batas struktur modal optimum. Oleh karena itu, perusahaan perlu mempertimbangkan tingkat non-debt tax shield dalam mengambil keputusan struktur modal. Jika perusahaan memiliki tingkat non-debt tax shield yang rendah maka perusahaan lebih baik menggunakan sumber dana eksternal dalam memenuhi kebutuhan struktur modal selama penggunaan dana eksternal tidak melampaui batas struktur modal optimum.

Hasil penelitian juga menunjukkan bahwa risiko bisnis berpengaruh positif terhadap struktur modal. Temuan penelitian ini konsisten 
dengan penelitian terdahulu yang menemukan bahwa tingginya tingkat risiko bisnis bisa dikarenakan tingginya penggunaan utang dalam memenuhi kebutuhan struktur modal. Selain itu, penelitian ini juga mendukung Pecking Order Theory yang menyatakan bahwa perusahaan lebih baik menggunakan pendanaan dari laba ditahan atau dana internal dibandingkan dengan utang. Hal ini karena pendanaan dari utang dapat meningkatkan terjadinya financial distress. Oleh karena itu, perusahaan perlu mempertimbangkan tingkat risiko bisnis dalam mengambil keputusan struktur modal. Jika perusahaan memiliki tingkat risiko bisnis yang tinggi maka lebih baik menggunakan dana internal dalam memenuhi kebutuhan struktur modal.

Penelitian ini berkontribusi dengan menyajikan faktor yang berpengaruh terhadap struktur modal dengan menggunakan data laporan keuangan perusahaan manufaktur di Indonesia. Penelitian berikutnya bisa merambah ke jenis industri lain untuk membandingkan pengaruh non-debt tax shield dan risiko bisnis dalam keputusan struktur modal serta mengetahui perbedaan struktur modal di masingmasing industri.

\section{DAFTAR RUJUKAN}

Properti Dan Real estate Di Indonesia. Jurnal Ekonomi Dan Keuangan 5(80): 1-20.

Chen, J., Jiang, C., dan Lin, Y. 2014. What Determine Firms Capital Structure in China? Managerial Finance, 40(10), 1024-1039.

Cortez, M. A., dan Susanto, S. 2012. The Determinants of Corporate Capital Structure: Eviedence From Japanese Manufacturing Companies. Journal of International Business Research 11(3): 121-134.
Dakua, S. 2018. Effect of Determinants on Financial Leverage in Indian Steel Industry: A Study on Capital Structure. International Journal of Finance Economic 24: 427-436.

De Angelo, H., dan Masulis, R. W. 1980. Optimal Capital Structure Under Corporate and Personal Taxation. Journal of Financial Economic 8: 3-29.

Dufour, D., Luu, P., dan Teller, P. 2018. The Influence of Cash Flow On the Speed of Adjustment to the Optimal Capital Structure. Research in International Business and Finance 45: 62-71.

Fahmi, Irham. 2011. Analisa Laporan Keuangan. Alfabeta. Bandung.

Fattouh, B., Harris, L., dan Scaramozzino, P. 2008. Non-linearity in the Determinants of Capital Structure: Evidence from UK firms. Empirical Economics 34(3): 417438.

Gao, R. 2016. An Empirical Study on the Influence of Non-Debt Tax Shield on the Choice of Corporate Debt Levels---Based On the Tax Preference Policy. International Journal of Business and Social Science 7(1): 201-212.

Gomez, G., Rivas, A. M., dan Lizarzaburu Bolanos, E. R. 2014. The Determinants of Capital Structure in Peru. Academia Revista Lationoamericana de Administration 27(3): 341-354.

Hery. 2014. Akuntansi Aset, Liabilitas dan Ekuitas. PT Grasindo. Jakarta.

Horne, Van dan Wachowicz. 2012. Prinsipprinsip Manajemen Keuangan. Edisi Ketigabelas. Salemba Empat. Jakarta.

Khémiri, W., dan Noubbigh, H. 2018. Determinants of Capital Structure: Evidence from Sub-Saharan African firm. The Quarterly Review of Economics and Finance: 1-20.

Köksal, B., dan Orman, C. 2014. Determinants 
of Capital Structure: Evidence From a Major Developing Economy. Small Business Economics 44(2): 1-28.

Kouki, M., dan Said, H. S. 2012. Capital Structure

Determinants: New Evidence from French Panel Data. International Journal of Business and Management 7(1): 214229.

Kraus, A., dan Litzenberger, R. H. 1973. A StatePreference Model of Optimal Financial Leverage. The Journal Oj Finance 28: 911-922.

Lim, T. C. 2012. Determinants of Capital Structure Empirical Evidence from Financial Services Listed Firms in China. International Journal of Economics and Finance 4(3): 191-203.

Lourenço, A. J., dan Oliveira, E. C. 2017. Determinants of Debt: Empirical Evidence on Firms in the District of Santarém in Portugal Determinantes. Contaduria y Administracion 62(2): 625643.

Martín, P. S., dan Hoffmann, P. S. 2017. Capital Structure in the Chilean Corporate Sector: Revisiting the Stylized Facts. Research in International Business and Finance.

Modigliani, F., dan Miller, M. H. 1958. The Cost of Capital, Corporation Finance and the Theory of Investment. The American Economic Review 48(3): 261-297.

Mulyadi, J. M. V, Yusuf, M., dan Juliandi. 2016. Pengaruh Profitabilitas , Tangibilitas, Risiko Bisnis, Pajak, Non Debt Tax Shield terhadap Struktur Modal serta Implikasinya terhadap Nilai Perusahaan. Jurnal Riset Akuntansi Dan Perpajakan 3(2): 251-263.

Murniati, S. 2016. Effect of Capital Structure, Company Size and Profitability on the Stock Price of Food and Beverage Companies Listed on the Indonesia
Stock Exchange Sitti. Information Management and Business Review 8(1): 23-29.

Myers, S. C. 1984. The Capital Structure Puzzle. The Journal of Finance 39(3): 575-592.

Myers, S. C., \& Majluf, N. S. (1984). Corporate financing and investment decisions when firms have informationthat investors do not have (No. w1396). National Bureau of Economic Research.

Noordin, M. A., dan Mohtar, S. 2014. Age : Does it Matter for Firms to Perform? International Journal of Academic Research in Business and Social Sciences 4(3): 252-260.

Pfaffermayr, M., Stockl, M., dan Winners, H. 2013. Capital Structure, corporate taxation and firm age. The Journal of Applied Public Economic 34(1): 109135.

Psillaki, M., dan Daskalakis, Æ. N. 2009. Are the Determinants of Capital Structure Country or Firm Specific ? Small Business Economics 33: 319-333.

Rouf, A. 2015. Capital Structure and Firm Performance of Listed Non-Financial Companies in Bangladesh. The International Journal of Applied Economics and Finance 9(1): 25-32.

Sharah, M., Herawati, dan Yunilma. 2014. Pengaruh Non-debt tax shield, Operating Leverage, dan Pertumbuhan Asset Terhadap Struktur Modal: 1-9.

Sheikh, N. A., dan Wang, Z. 2011. Determinants of Capital Structure An Empirical Study of Firms in Manufacturing Industry of Pakistan. Managerial Finance 37(2): 117133.

Sofat, R., dan Singh, S. (2017). Determinants of Capital Structure: An Empirical Study of Manufacturing Firms in India. International Journal of Law and Management 59(6): 1029-1045. 
Sugeng, Bambang. 2017. Manajemen Keuangan Fundamental. Deepublish. Yogyakarta.

Tamam, D. B., dan Wibowo, S. 2017. Pengaruh Tangibility, Profitability, Liquidity, Firm Size dan Non-Debt Tax Shield terhadap Struktur Modal Pada Sektor Pertanian. Jurnal Bisnis Dan Akuntansi 19(1): 129_ 135.

Wijaya, E., dan Jessica. 2017. Against Sector Companies in the Property dan Real Estate Listed in Indonesia 5(4): 440-451. Yunita, S., dan Aji, T. S. 2018. Pengaruh Likuiditas, Tangibility, Growth Opportunity, Risiko Bisnis, dan Ukuran Perusahaan Terhadap Struktur Modal. Ilmu Manajemen 6(4): 409-416. 